\title{
Acute myocardial infarction with occlusion of all three main epicardial coronary arteries: when Mother Nature takes care more than physicians
}

\author{
Daniel E. Monopoli $\cdot$ Luigi Politi • \\ Fabio Sgura - Rosario Rossi • \\ Maria G. Modena $\cdot$ Giuseppe M. Sangiorgi
}

Received: 18 September 2009/ Accepted: 17 December 2009/Published online: 13 November 2010

(C) Springer 2010

\begin{abstract}
Double-arterial coronary stent thrombosis in acute myocardial infarction (AMI) is an infrequent but severe complication, especially when the third main coronary artery is chronically occluded. The conus artery (CA) can serve as a major source of collateral when the left anterior descendent coronary artery (LAD) becomes obstructed. We report a case of a 48-year-old man presenting with AMI due to a very late double-arterial stent thrombosis (ST) following drug-eluting stent implantation and a chronic occlusion of LAD collateralized by a large anomalous $\mathrm{CA}$, which provided for the entire vascularization of the coronary tree.
\end{abstract}

Keywords Conus artery $\cdot$ Collateral circulation $\cdot$ Stent thrombosis

\section{Introduction}

Stent thrombosis following drug-eluting stent (DES) is an infrequent but very severe complication with consequences that are frequently catastrophic $[1,2]$.

Collateral circulation after AMI has been associated with limited infarct size and improved ventricular function $[3,4]$. The conus artery in patients with coronary artery disease can serve as a major source of collateral circulation

D. E. Monopoli $(\varangle) \cdot$ L. Politi · F. Sgura · R. Rossi ·

M. G. Modena - G. M. Sangiorgi

Department of Cardiology, Policlinico University Hospital

of Modena, Via del Pozzo 71, 41124 Modena, Italy

e-mail: danielmonopoli@libero.it when the left anterior descendent coronary artery (LAD) becomes obstructed, and to a lesser extent can also collateralize the distal segment of an obstructed right coronary artery (RCA) [5].

We report a case of a 48-year-old man who presented an acute myocardial infarction (AMI) with a very late doublearterial stent thrombosis following DES implantation and a chronic occlusion of the LAD collateralized by a conus artery.

\section{Case description}

In November 2005 a 46-year-old man was admitted to our hospital for a non-ST segment elevation myocardial infarction. Echocardiogram revealed an ejection fraction of $55 \%$. Coronary catheterization revealed critical stenoses of the middle RCA and proximal first obtuse marginal (OM1) artery, and chronic total occlusion of the LAD. The patient refused coronary artery bypass graft surgery. The critical stenoses of the middle RCA and proximal OM artery were treated with angioplasty and the implantation of two single DESs (Sirolimus-eluting stents; Cypher, Cordis/Johnson \& Johnson, Miami Lakes, FL, USA), respectively. The patient's hospital course was uneventful and he was discharged on aspirin and clopidogrel for 12 months. He was asymptomatic at 23 months' follow-up. In October 2007, the patient (48 years old at the time) was urgently transferred to our catheterization unit in cardiogenic shock with total atrioventricular block and ST-segment elevation in both the inferior and lateral electrocardiographic leads. Temporary right ventricular pacing and an intra-aortic balloon pump were introduced in addition to high-dose dopamine infusion. The patient required endotracheal intubation during diagnostic catheterization for respiratory 
instability. Echocardiogram revealed an ejection fraction of $30 \%$, with infero-postero-lateral akinesia without mechanical complication. Coronary angiography revealed simultaneous drug-eluting stent thrombosis occlusion of the middle right coronary artery (RCA) and proximal first obtuse margin artery (OM1), with chronic total occlusion of the left anterior descending (LAD) coronary artery. Selective catheterization of an enlarged conus artery that originated from a separate ostium in the right sinus of Valsalva showed extensive collateral circulation to the distal left anterior descendent coronary artery and weak flow to the OM1 (Fig. 1a-d). Lesions of the right coronary and obtuse marginal were easily crossed, predilated and treated with bare-metal stents. Abciximab infusion was started and $600 \mathrm{mg}$ of clopidogrel were administered. The patient slowly recovered and was extubated for several days after the initial event. He was discharged on aspirin and clopidogrel on day nine. He remained asymptomatic. Angiographic follow-up was performed at nine months, which showed stent patency (Fig. 2a-d). He was still asymptomatic after one year of follow-up.

\section{Discussion}

This case presents three particular characteristics. The first was simultaneous double arterial thrombosis inside Cypher stents in the RCA and OM1 in a patient with chronic occlusion of the proximal LAD, which caused an acute MI that rapidly deteriorated into a shock state. It is possible that the initial presentation was of inferior infarction, which caused low blood pressure that rapidly provoked the ST into the OM due to reduced flow. The patient had no other risk factors such as diabetes, renal failure, or depressed cardiac function that may increase the long-term risk for stent thrombosis [2]. Furthermore, no angiographic characteristics such as bifurcation or long lesions which would have placed him at increased risk of ST were present. Moreover, at the time of the event, the patient had been off dual antiplatelet drug therapy for a year, and was taking only acetylsalicylic acid. Very late ST is reported to occur in about $0.4-0.6 \%$ of DES-treated patients [2]. Very late thrombosis is probably a multifactor phenomenon that is largely unpredictable and may relate to a lack of
Fig. 1 a Right anterior oblique, caudal view of the left coronary angiography shows total occlusions of the proximal LAD and proximal OM1. b Left anterior oblique view of the right coronary angiography shows occlusions of the mid RCA. c, d Right and left anterior oblique, cranial views show the selective catheterization of a separate conus artery that was free from significant stenosis, which supplied good collateral flow in a retrograde manner to the occluded LAD artery and weak flow to the occluded OM1
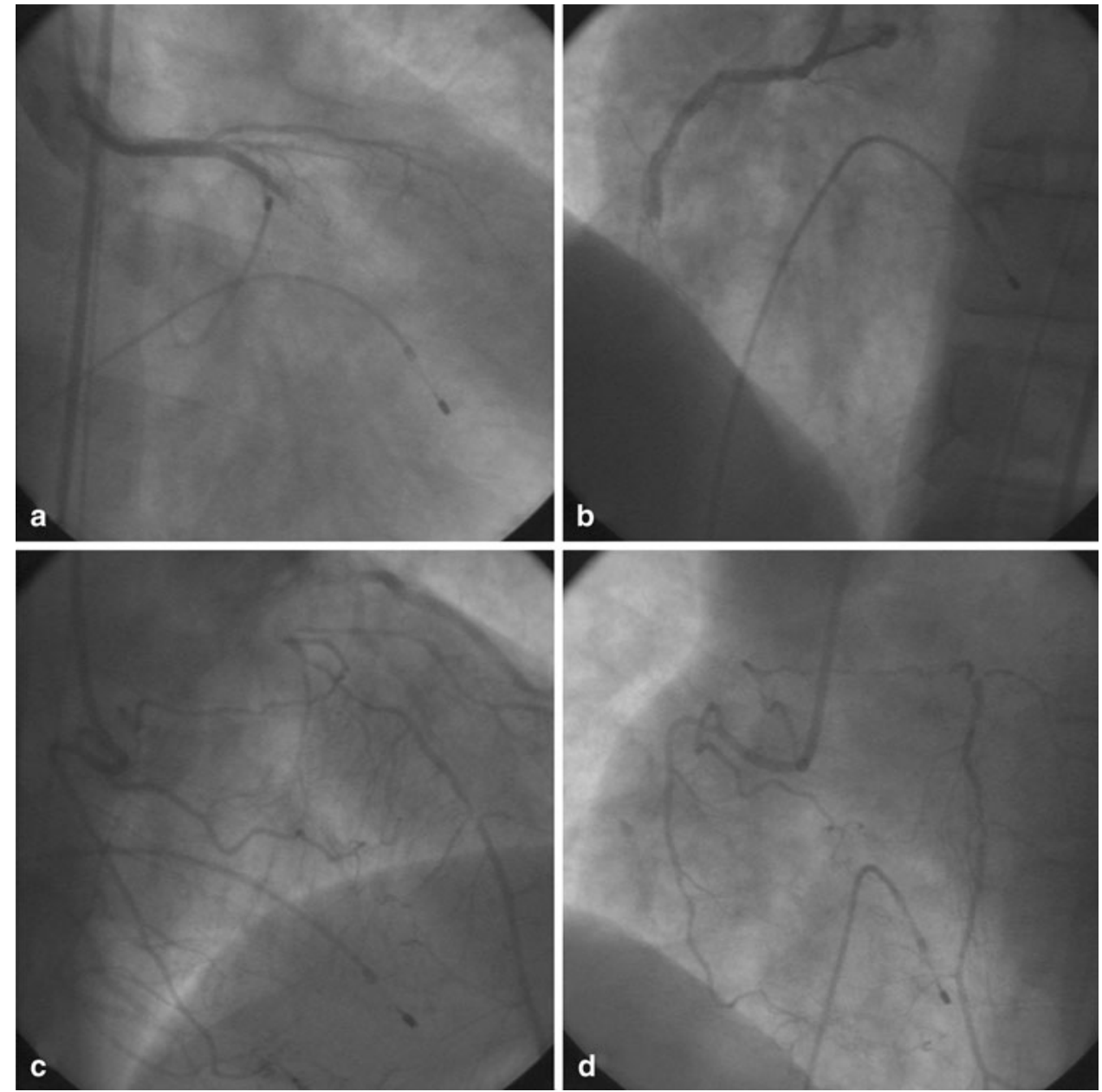
Fig. 2 a Right anterior oblique, caudal view of the left coronary angiography shows patency after 1 year of OM1. b Left anterior oblique view of the RCA angiography shows patency after 1 year. c, d Right and left anterior oblique, cranial views with simultaneous injection of contrast into the LAD and into the conus artery with a JR 5F catheter (black arrows) show collateral flow to the occluded LAD (white arrow) and the patency of the $\mathrm{OM}$
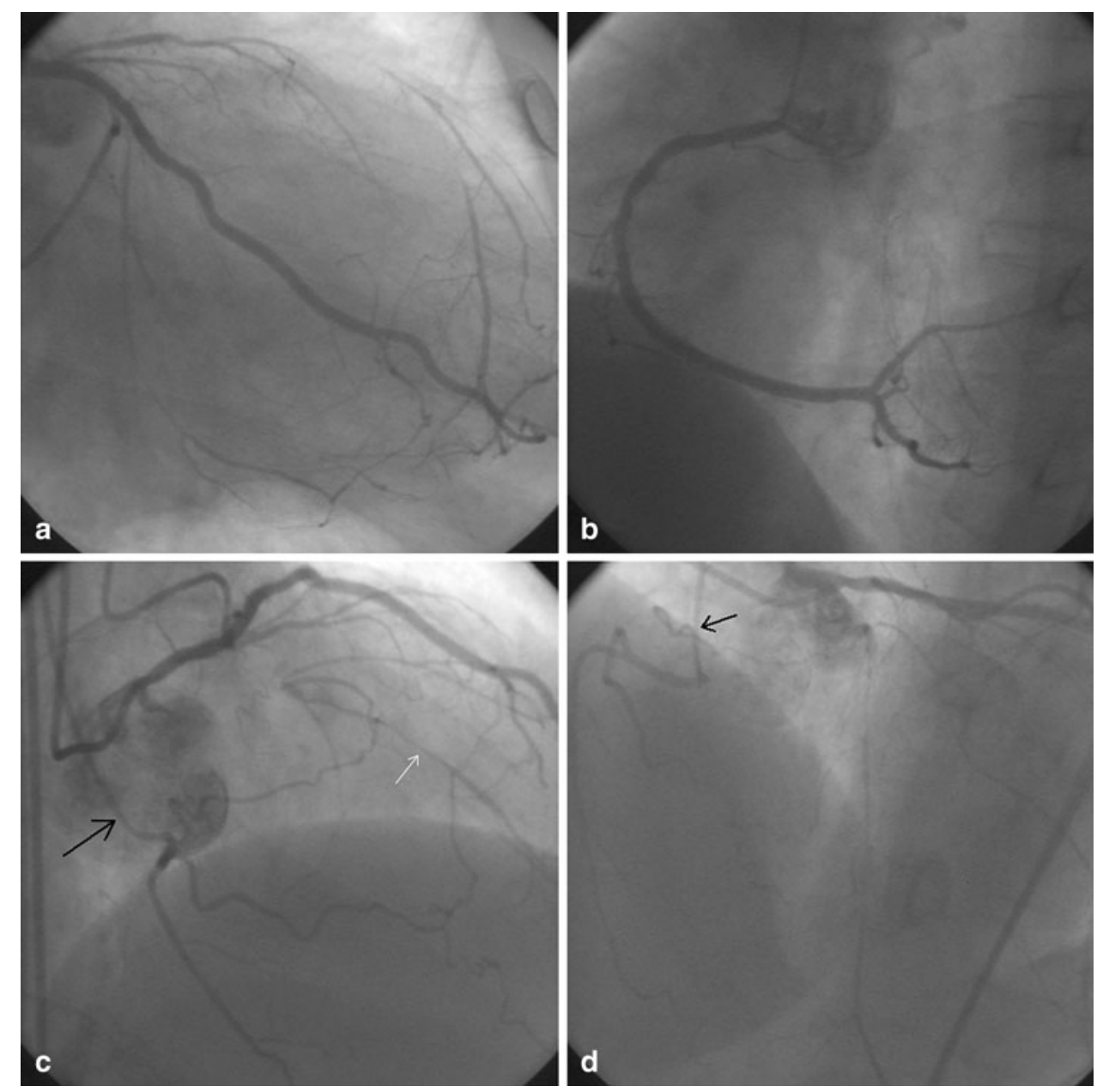

endothelial healing and/or an ongoing prothrombotic vascular inflammatory response to a drug or polymer $[1,6-8]$.

Currently, there is great uncertainty about the optimal duration of dual-antiplatelet medications following DES deployment. However, in this case, we advised the patient to continue the clopidogrel and aspirin intake permanently, or for as long as they could be tolerated.

Many strategies have been employed for the treatment of late and very late stent thrombosis, such as thrombus aspiration, balloon angioplasty, and stent deployment, as well as simple drug treatment [9]. Better outcomes have been reported when thrombus aspiration and percutaneous interventions are used together [10]. Evidence from the most recent studies suggests that adjunctive manual thrombectomy in patients undergoing primary percutaneous coronary intervention for ST-elevation myocardial infarction is associated with better epicardial and myocardial perfusion, less distal embolization, and a significant reduction in mortality [11-15]. Although many studies on adjunctive thrombectomy in AMI have excluded high-risk patients with cardiogenic shock and hemodynamic instability, it is possible that this group may benefit from this procedure. In our case, the patient was in cardiogenic shock and severely bradycardic, so we preferred immediate recanalization by conventional angioplasty. Due to the suboptimal results of the balloon, we then turned to stenting.

The second interesting characteristic of the case was that the patient tolerated the acute closure of the two remaining vessels due to the presence of an aberrant conus branch arising from the right coronary ostium. The abnormal origin of the conus artery was recognized several years ago [16], and has been reported to arise independently of the right sinus of Valsalva in $45-50 \%$ of autopsied cases. Its importance as a collateral flow pathway in patients with total obstruction of the LAD has been previously described [5, 6].

Finally, the third feature of the case was that the conus artery was the only coronary artery that was spared from significant atherosclerotic disease.

\section{Conclusion}

Because the degree of distal filling via collateral circulation affects therapeutic decisions, it is important to attempt to 
visualize the conus artery adequately whenever the LAD or RCA is obstructed. This artery can, as demonstrated by this case, provide complete revascularization of the entire coronary tree when acute occlusion occurs. As stated by Voltaire (1694-1778), "The art of medicine consists in amusing the patient (with stents) while nature cures the disease."

\section{References}

1. Holmes DR, Kereiakes DJ, Laskey DK, Colombo A, Ellis SG, Henry TD, Popma JJ, Serruys PW, Kimura T, Williams DO, Windecker S, Krucoff MW (2007) Thrombosis and drug-eluting stents. J Am Coll Cardiol 50:109-118

2. Bavry AA, Kumbhani DJ, Helton TJ, Borek PP, Mood GR, Bhatt DL (2006) Late thrombosis of drug-eluting stents: a meta-analysis of randomized clinical trials. Am J Med 119:1056-1061

3. Gensini GG, Bruto Da Costa BC (1969) The coronary collateral circulation in living man. Am J Cardiol 24:393-400

4. Habib GB, Heibig J, Forman SA, Brown BG, Roberts R, Terrin ML, Bolli R (1991) Influence of coronary collateral vessels on myocardial infarct size in humans: results of phase I thrombolysis in myocardial infarction (TIMI) trial: TIMI investigators. Circulation 83:739-746

5. Levin DC, Kauff M, Baltaxe HA (1973) Coronary collateral circulation. Am J Roentgenol Radium Ther Nucl Med 19(3):463-473

6. Ozer N, Tangurek B, Firat F (2008) Effects of drug-eluting stents on systemic inflammatory response in patients with unstable angina pectoris undergoing percutaneous coronary intervention. Heart Vessels 23(2):75-78

7. Lüscher TF, Steffel J, Eberli FR, Joner M, Nakazawa G, Tanner FC, Virmani R (2007) Drug-eluting stent and coronary thrombosis: biological mechanisms and clinical implications. Circulation 115:1051-1058
8. Jaffe R, Strauss BH (2007) Late and very late thrombosis of drugeluting stents: evolving concepts and perspectives. J Am Coll Cardiol 50:119-127

9. Karakurt O, Cagirci G, Kilic H, Akdemir R (2009) Resolution of late sirolimus-eluting stent thrombosis after tirofiban treatment. Heart Vessels 24(5):388-390

10. De Vita M, Burzotta F, Trani C, Romagnoli E, Talarico GP, Porto I, Leone AM, Biondi-Zoccai GG, Niccoli G, Rebuzzi AG, Mongiardo R, Mazzari MA, Schiavoni G, Crea F (2008) Urgent PCI in patients with stent thrombosis: an observational singlecenter study comparing thrombus aspiration and standard PCI. J Invasive Cardiol 20(4):161-165

11. Bavry AA, Kumbhani DJ, Bhatt DL (2008) Role of adjunctive thrombectomy and embolic protection devices in acute myocardial infarction: a comprehensive meta-analysis of randomized trials. Eur Heart J 29(24):2989-3001

12. De Luca G, Dudek D, Sardella G, Marino P, Chevalier B, Zijlstra F (2008) Adjunctive manual thrombectomy improves myocardial perfusion and mortality in patients undergoing primary percutaneous coronary intervention for ST-elevation myocardial infarction: a meta-analysis of randomized trials. Eur Heart $\mathrm{J}$ 29(24):3002-3010

13. Svilaas T, Vlaar PJ, van der Horst IC, Diercks GF, de Smet BJ, van den Heuvel AF, Anthonio RL, Jessurun GA, Tan ES, Suurmeijer AJ, Zijlstra F (2008) Thrombus aspiration during primary percutaneous coronary intervention. N Engl J Med 358:557-567

14. Vlaar PJ, Svilaas T, van der Horst IC, Diercks GF, Fokkema ML, de Smet BJ, van den Heuvel AF, Anthonio RL, Jessurun GA, Tan ES, Suurmeijer AJ, Zijlstra F (2008) Cardiac death and reinfarction after 1 year in the thrombus aspiration during percutaneous coronary intervention in acute myocardial infarction Study (TAPAS): a 1-year follow-up study. Lancet 371:1915-1920

15. Srinivasan M, Rihal C, Holmes DR, Prasad A (2009) Adjunctive thrombectomy and distal protection in primary percutaneous coronary intervention: impact on microvascular perfusion and outcomes. Circulation 119(9):1311-1319

16. Schlesinger MJ, Zoll PM, Wessler S (1949) The conus artery: a third coronary artery. Am Heart J 38:823 